\title{
Cirandinhas $n^{\circ} 9$ de Heitor Villa- Lobos: Uma proposta pedagógica para a formação musical
}

Cirandinhas $n^{\circ} 9$ by Heitor Villa-Lobos: A pedagogical proposal for the musical formation

\section{Marta Macedo Brietzke I}

1 Marta Macedo Brietzke, Doutoranda em Música no Programa de Pós-Graduação em Música da Escola de Comunicações e Artes da Universidade de São Paulo, Área de concentração: Criação Musical, Linha de Pesquisa: Questões Interpretativas, Orientador: Professor Doutor Fabio Soren Presgrave, Coorientador: Professor Doutor Mário André Wanderley Oliveira, Email: martabrietzke@gmail.com. 
RESUMO: Este trabalho descreve uma experiência pedagógica/musical realizada em Porto Alegre/RS (Brasil), no ano de 2016, que consistiu na adaptação das Cirandinhas $n^{o}$ 9 de Heitor Villa-Lobos, original para piano, para orquestra formativa de violoncelos. Estruturou-se tendo como base as considerações de Quinteiro (2002), Shimabuco (2012), Pilger (2013) e Machado (2015). Levou em consideração elementos idiomáticos do violoncelo, abordagens relativas às texturas musicais utilizadas pelo compositor, tecendo uma relação com a arte e com o "estado de infância".

PALAVRAS-CHAVE: Heitor Villa-Lobos, Cirandinhas n ${ }^{\circ}$ 9, Orquestra formativa de violoncelos, Estado de infância

ABSTRACT: This work describes a pedagogical / musical experience held in Porto Alegre/RS (Brasil), in the year 2016, which consisted of the adaptation of the Cirandinhas no. 9 by Heitor Villa-Lobos, original for piano, for the orchestral ensemble of cellos. It was structured based on the considerations of de Quinteiro (2002), Shimabuco (2012), Pilger (2013) and Machado (2015). It took into account idiomatic elements of the cello, approaches related to the musical textures used by the composer, making relationship with art and the "state of childhood".

KEYWORDS: Heitor Villa-Lobos, Cirandinhas nº 9, Orchestral ensemble of cellos, State of childhood. 


\section{Introdução}

O objetivo deste trabalho é relatar parte de um processo de ensino e aprendizagem das Cirandinhas $n^{\circ} 9$ (1925) de Heitor Villa-Lobos (1887-1952), originais para piano, em uma adaptação para orquestra formativa de violoncelos. Busca evidenciar as características intrínsecas ao trabalho do compositor de valorização do repertório instrumental didático e as escolhas pedagógicas realizadas na adaptação, montagem e performance da peça, para que essas características fossem mantidas na adaptação para a nova formação instrumental. Foi baseado nas considerações de Shimabuco (2012) e Pilger (2013), também relacionando-se com o trabalho de Quinteiro (2002) e Machado (2015), com apoio em observações realizadas em um trabalho pedagógico desenvolvido em Porto Alegre, no ano de 2016.

Villa-Lobos é muito conhecido por seu trabalho educacional direcionado a atividades pedagógicas para as crianças, principalmente ao canto coral. As Cirandinhas relacionam-se com essas propostas e são uma série de 12 peças escritas originalmente para piano, para serem executadas pelo público infantil. Em cada uma dessas peças, Villa-Lobos compartilha, segundo sua linguagem e abordagem composicional, canções da tradição oral infantil brasileira, como por exemplo Se esta rua fosse minha; Carneirinho, Carneirão; Vamos maninha, vamos; entre outras. Segundo Lago, Barboza e Barbosa (2009, p. 43), os temas do cancioneiro brasileiro percorrem toda a obra de Villa-Lobos e fornecem "uma chave indispensável para a compreensão do universo de compositor". Apesar de Villa-Lobos ter sido violoncelista e ter escrito um grande número de peças para esse instrumento, não se dedicou à tarefa de escrever peças com potencial formativo para o violoncelo, ou direcionadas para o público infantil desse instrumento. A proposta realizada buscava, então, possibilitar o acesso de violoncelistas, em fase formativa, à obra de Villa-Lobos.

\section{Contextualização e revisão bibliográfica:}

Conforme apontado pela literatura, o ensino dos instrumentos musicais no Brasil está, em grande parte, desconectado com uma série de tendências que vêm sendo trazidas 
pela educação musical desde meados do século XX. Fonterrada (2008), por exemplo, acredita, a partir de suas observações como docente, que muito desse descompasso ocorre em função do ensino de instrumento ainda estar condicionado a concepções próprias do século XIX, como a ênfase na formação de instrumentistas virtuosos (FONTERRADA, 2008, p. 81). As considerações da autora são, muitas vezes, observadas por outros professores no cotidiano do trabalho educativo.

Da mesma forma, Carrasqueira (2017), com base em suas experiências como professor e instrumentista, aponta também a escassa abordagem da música brasileira no ensino universitário de diversos instrumentos. O autor, ao discutir essa questão, adota uma visão crítica, tanto em termos sociais, quanto políticos. Enfatiza, em sua análise, o ensino de instrumentos no contexto universitário, porém, sendo o modelo de ensino aplicado pelas universidades adotado em outros âmbitos, acredito que essa crítica também possa ser ampliada para outros contextos, apesar de ainda não dispormos, até o momento, de resultados de pesquisas empíricas que confirmem esses dados observados, muito frequentemente, no dia a dia dos professores de instrumento.

Como é possível que nossos professores, vivendo num país de cultura musical riquíssima e forte, desprezem essa possibilidade? Será isso reflexo de uma mentalidade colonizada, que considera a cultura da metrópole superior à do país colonizado, o chamado complexo de vira-lata detectado pelo dramaturgo Nelson Rodrigues? O fato é que a maioria, se não a totalidade, dos nossos professores baseia seu ensino em métodos europeus. Provavelmente pelo seu desconhecimento da música brasileira, o que gera o preconceito e a tendência a discriminá-la e subestimá-la, sobretudo a de origens tradicional, folclórica ou popular. Não percebem sua riqueza e sua enorme importância num projeto pedagógico e de construção de uma identidade (CARRASQUEIRA, 2017, p. 34).

Tendo em vista o apontado pelos autores citados, o trabalho proposto com a adaptação, montagem e performance da Cirandinhas $n^{\circ} 9$ visava diminuir algumas dessas lacunas observadas, também, durante o trabalho pedagógico realizado como professora de violoncelo em Porto 
Alegre. Procurava adotar estratégias de ensino em que fossem abordadas a aproximação dos estudantes com a música brasileira de concerto. Ao mesmo tempo, procurava aproximar os alunos de canções infantis da tradição oral brasileira, considerando que essas canções viabilizam elementos importantes para a formação do imaginário e da criatividade musical, em diálogo com os apontamentos de Machado (2015).

Machado (2015) cita, por exemplo, que na tradição oral os personagens envolvidos em uma narrativa representam concepções diferentes das encontradas em outras abordagens. Segundo a autora, os personagens "não são pessoas, mas configurações de possibilidades: figuram metaforicamente modos de ação da mente, da afetividade, da percepção e da intuição, tais como funcionam internamente, das mais variadas formas, em cada ser humano" (MACHADO, 2015, p. 88). Sendo as canções da tradição oral repletas de "personagens", como, por exemplo, o "anjo" de Se esta rua fosse minha, ou a "maninha" de Vamos maninha, vamos", também cabe às canções a representação das configurações de possibilidades, conforme apontado pela autora.

Considerando os objetivos estabelecidos para o trabalho pedagógico, foi necessário, no âmbito da técnica do instrumento, a adequação às características idiomáticas ${ }^{2}$ do violoncelo, enfatizadas, sobretudo, no trabalho de Pilger (2013). O autor aponta algumas dessas características que se adequam muito bem ao processo formativo, como o uso de cordas soltas ${ }^{3}$, de cordas duplas ${ }^{4}$

2 Na música, o que identifica o idiomatismo em uma obra é utilização das condições particulares do meio de expressão para o qual ela é escrita (instrumento/s, voz/es, multimídia ou conjuntos mistos). As condições oferecidas por um veículo incluem aspectos como: timbre, registro, articulação, afinação e expressões. Quanto mais uma obra explora aspectos que são peculiares de um determinado meio de expressão, utilizando recursos que o identificam e o diferenciam de outros meios, mais idiomática ela se torna. Neste sentido, se comparado à aplicação linguística do conceito, o idioma de um instrumento musical seria o equivalente a um fonema específico de uma língua falada. (FRAGA, 2005, p. 299).

3 Técnica instrumental relativa aos instrumentos de cordas em que se utilizam notas provenientes do som previsto pelos fabricantes das cordas, sem a utilização de nenhuma digitação adicional.

4 Técnica instrumental relativa aos instrumentos de cordas em que se tocam duas notas do instrumento simultaneamente, porém, cada uma das notas é extraída de diferentes cordas do instrumento. 
e de técnicas estendidas 5 . Também foi levado em consideração o trabalho de Shimabuco (2012), em relação ao uso das texturas ${ }^{6}$ na obra villalobiana. A autora ressalta que os mesmos recursos utilizados por Villa-Lobos em obras de maior envergadura foram mantidos na concepção das Cirandinhas, o que valoriza o público infantil (SHIMABUCO, 2012, p. 49). A autora aponta, principalmente, o uso de pedais ${ }^{7}$ e ostinatos $^{8}$, o uso de oitavas paralelas ${ }^{9}$ entre as vozes e o uso de terças paralelas ${ }^{10}$ entre as vozes. Esses recursos, citados pela autora, constituem-se em elementos que proporcionam, tanto na instrumentação original, quanto na escolhida para a adaptação, a adequação da peça como proposta pedagógica.

Além dos aspectos citados, também foi trazido para o trabalho a concepção de imitação. Essa concepção foi utilizada, nesse trabalho, como o referenciar-se a elementos da natureza

5 Tradicionalmente associada às técnicas de performance instrumental, a expressão técnicas estendidas se tornou comum no meio musical a partir da segunda metade do século XX, referindo-se aos modos de tocar um instrumento ou utilizar a voz que foge aos padrões estabelecidos, principalmente no período clássico-romântico. Em um contexto mais amplo, porém, percebe-se que em várias épocas a experimentação de novas técnicas instrumentais e vocais e a busca por novos recursos expressivos resultaram em técnicas estendidas. Nesta acepção, pode-se dizer que o termo técnica estendida equivale a técnica não-usual: maneira de tocar ou cantar que explora possibilidades instrumentais, gestuais e sonoras pouco utilizadas em determinado contexto histórico, estético e cultural (PADOVANI; FERRAZ, 2011, p. 1).

6 Termo usado para referir-se a aspectos sonoros de uma estrutura musical. Aplica-se tanto aos aspectos verticais de uma obra ou passagem, por exemplo, o modo pelo qual partes individuais ou vozes são colocadas juntas, ou a atributos como tom de cor ou ritmo, ou a características de desempenho como articulação e nível dinâmico (Grove Music Online, 2010, tradução nossa).

7 Termo musical utilizado para descrever a manutenção ou permanência de uma mesma nota, ou de combinações de notas, durante um certo período de tempo durante uma peça musical.

8 Termo usado para se referir à repetição de um padrão musical muitas vezes em sucessão, enquanto outros elementos musicais, geralmente, estão mudando. (Grove Music Online, 2001, tradução nossa).

9 Movimentos melódicos sucessivos paralelos em oitvas (REGO; GLOEDEN, 2010, p.1).

10 Movimentos melódicos sucessivos paralelos em terças (REGO; GLOEDEN, 2010, p.1). 
e do entorno, bem como a qualidades psicológicas. Com referência às ideias de Emmerson (1986), considero a "imitação não só da natureza, mas também de aspectos da cultura humana usualmente não associados de modo direto ao material musical" (EMMERSON, 1986, p. 5, tradução de FREIRE). A utilização dessa ideia teve como ponto de partida a proposta de paisagens e entornos musicais e extra-musicais, em que eram sugeridos aos alunos elementos interpretativos, com base na memória de fenômenos da natureza e de caráter psicológico.

Alguns trabalhos semelhantes à abordagem realizada já foram apresentados por outros autores, porém, com diferentes enfoques. Pereira (2011) apresentou a reelaboração do Choros $n^{o} 5$ (1925), na qual propõe abordagens de processos composicionais de Villa-Lobos em coincidência com o idiomatismo dos instrumentos da orquestra. Carrasqueira (2017) propõe uma abordagem que utiliza peças brasileiras inspiradas em diferentes estilos da música popular, como o choro, a valsa e o baião. Sob o ponto de vista do ensino de violoncelo, Carvalho (2010) e Souza (1998) apontaram considerações sobre a importância do uso de música brasileira no ensino do instrumento. Brietzke e Villena (2014) abordam proposta semelhante à apresentada aqui: elaboração de material didático voltado ao ensino coletivo do violoncelo, utilizando características imitativas no trabalho de composição.

\section{Metodologia e aplicação das atividades}

A aplicação da adaptação da peça ocorreu em aulas coletivas de violoncelo, em encontros semanais durante um semestre. Esse trabalho foi realizado tendo como ponto de partida a observação participante, que visava conhecer as impressões dos alunos em relação à peça, bem como o conforto ou desconforto gerados durante a execução e as reações afetivas dos estudantes. Os dados foram analisados tendo em vista as impressões exteriorizadas nas aulas, a minha impressão como professora e as referências bibliográficas utilizadas como suporte. A performance da peça foi realizada em diversos momentos, entre eles, em sua estreia no concerto de encerramento do Encontro de Violoncelos do RS, em julho de 2016 e disponibilizada no site youtube ${ }^{11}$.

11 Disponível em: https://youtu.be/oYhmDvMyvJU 
O trabalho foi direcionado para alunos de violoncelo de nível intermediário de um projeto social, situado no bairro Lomba do Pinheiro, na periferia de Porto Alegre. Esse projeto, intitulado Filarmônica de Violoncelos-Tchêllistas, objetiva o ensino e aprendizagem do violoncelo em aulas coletivas e individuais. Todos os alunos participam da orquestra de violoncelos, que tem repertório direcionado para atender diferentes níveis de desenvolvimento, desde a iniciação até o início da profissionalização. Engloba adaptações e arranjos de obras do repertório erudito de concerto, peças do cancioneiro brasileiro, da música popular brasileira infanto-juvenil e de outros estilos com os quais os alunos estão familiarizados, como o rock. Os alunos são oriundos de famílias com baixo poder aquisitivo e, na grande maioria das vezes, são motivados ao estudo da música por meio das mídias eletrônicas, principalmente por bandas pop que utilizam acompanhamento de instrumentos de cordas friccionadas.

Em relação a propostas ligadas ao idiomatismo do violoncelo, podemos citar a escolha da tonalidade ${ }^{12}$ de Ré maior, tonalidade que foi mantida na adaptação para violoncelos. Essa tonalidade adequa-se muito bem ao violoncelo em função das reverberações harmônicas provenientes das cordas soltas do instrumento, respectivamente, lá, ré, sol e dó (da corda mais aguda à mais grave). Segundo Pilger (2013), Villa-Lobos utilizava tonalidades que evidenciavam as cordas soltas na maioria das obras escritas para instrumentos de cordas friccionadas (violino, viola, violoncelo e contrabaixo) e para o violão (PILGER, 2013, p. 208). Além de apresentarem vantagens musicais e timbrísticas, conforme analisado por Pilger (2013), essa proposta adequa-se, também, a obras com fins didáticos, por serem as cordas soltas de fácil execução no instrumento, geralmente configurando-se em um dos primeiros conteúdos desenvolvidos no processo de aprendizagem do violoncelo.

12 Termo usado pela primeira vez por Choron em 1810 para descrever o arranjo do dominante e subdominante acima e abaixo da tônica e, assim, diferenciar a organização harmônica da música moderna (tonalité moderne) daquela da música anterior (tonalité antique). Uma das principais categorias conceituais no pensamento musical ocidental, o termo mais frequentemente refere-se à orientação de melodias e harmonias em direção a uma classe de altura referencial (ou tônica). No sentido mais amplo possível, no entanto, refere-se a arranjos sistemáticos de fenômenos de alturas e relações entre elas (HYER, 2001, tradução nossa). 


\begin{abstract}
As vantagens do uso das cordas soltas são inúmeras, mas uma das principais é a de aumentar a gama sonora do instrumento, $\mathrm{O}$ espectro harmônico de uma corda solta é muito maior do que de uma presa. Ao usarmos as cordas soltas, estamos deixando o instrumento vibrar em toda a sua capacidade, pois, por mais que possamos pressionar uma corda, em função do contato que dela com a pele, acontece um abafamento, pois a ponta do dedo é bem diferente da pestana do instrumento, que geralmente é feita de ébano, (PILGER, 2013, p. 208)
\end{abstract}

A Cirandinhas $\mathrm{n}^{\circ} 9$ foi originalmente escrita a duas vozes, mas, na adaptação para os violoncelos, foi adotada a divisão a três vozes a fim de proporcionar maior facilidade de leitura para os estudantes. As diferenças entre a primeira e segunda voz são muito pequenas e estão relacionadas, principalmente, às oitavas paralelas, propostas na segunda seção. A peça está estruturada em duas seções bem definidas, característica marcante nas obras do compositor (SALLES, 2009, p. 41). A primeira seção é marcada pela alternância entre linhas melódicas e um pedal, com a repetição simultânea das notas ré e mi, entre as vozes superior e inferior. Enquanto a voz superior realiza o pedal, a voz inferior executa linha melódica na região grave do violoncelo. Posteriormente, enquanto a voz inferior realiza o pedal, a voz superior executa a melodia na região aguda do violoncelo.

A segunda seção da peça corresponde à melodia da canção Carneirinho, carneirão, executada pela voz superior, com um acompanhamento proposto pela voz inferior, sendo mantido, também, em quase metade da seção, um pedal de ré. É proposta uma grande variação de caráter, que passa do "energético" da primeira seção ao "leve" e "brincalhão" na segunda parte. Também é proposta pelo compositor a variação de andamento entre as seções, sendo que a segunda seção é executada num andamento mais lento em relação a primeira parte da música. Na aplicação da performance em Porto Alegre, foi utilizada, como recurso pedagógico, a associação de ideias presentes no título da peça com elementos imitativos. As melodias da primeira seção foram classificadas conforme suas características timbrísticas, rítmicas e de caráter. A melodia executada pelas cordas graves foi associada ao "carneirão", enquanto a melodia executada pelas cordas agudas foi associada ao "carneirinbo". Além das qualidades timbrísticas, a melodia correspondente ao "carneirão" utiliza figuras rítmicas com divisões de 
colcheias e semicolcheias e proporciona um caráter "pesante", enquanto a melodia correspondente ao "carneirinho" utiliza divisões com colcheias pontuadas e fusas, proporcionando um caráter mais leve, ou "saltitante". Essa associação foi proposta aos alunos, incentivando-os a encontrarem relações entre características que representariam o "carneirão" e o "carneirinho", respectivamente.

De maneira semelhante, as notas que dão suporte à melodia da primeira seção (respectivamente, o pedal das notas ré e mi) também foram associadas com imagens externas à música. $\mathrm{O}$ uso dessas notas permite que os alunos possam tocar simultaneamente, sendo a nota ré emitida através do uso da corda solta ré e a nota mi emitida através da corda presa sol na quarta posição ${ }^{13}$ da mão esquerda. Essa posição é uma das que mais oferece conforto de execução para os estudantes, sendo assim, adequa-se muito bem a uma peça com caráter didático.

Foi solicitado que os alunos executassem essas notas de suporte buscando "imitar" o som das rabecas nordestinas, que utilizam, com frequência, esse mesmo recurso, ou seja, manter uma nota da corda solta soando simultaneamente às demais notas. Essa associação foi feita solicitando aos alunos que produzissem a sonoridade executando o pedal proposto por Villa-Lobos, na região conhecida como sul tasto I4, por oferecer maior aproximação com o som das rabecas. Segundo Pilger (2013), o uso das cordas duplas também era um recurso que Villa-Lobos utilizava com frequência em suas composições para violoncelo e outros instrumentos de cordas, a fim de "aumentar as possibilidades harmônicas das peças" (PILGER, 2013, p. 205). Sendo assim, o uso desse mesmo recurso em uma peça com caráter didático configura-se como uma aproximação com os recursos utilizados por ele em tais composições.

13 Posição da mão esquerda no violoncelo, onde a mão do instrumentista se posiciona quatro notas acima da posição básica. A digitação no violoncelo se estrutura em diferentes posições, que iniciam na chamada meio-posição, e se estruturam, conforme a maioria dos autores, em intervalos de semitons ou de tons inteiros. A sistematização das posições do violoncelo mais utilizada é a proposta por Duport, ainda no século XIX (SUETHOLZ, 2011, p. 39).

14 Técnica de arco do violoncelo, na qual o violoncelista posiciona o arco mais afastado do ponto de contato com a corda tradicionalmente utilizado de maneira padrão, o que resulta na produção de uma sonoridade mais “sombria” e com menos volume sonoro (SUETHOLZ, 2011, p. 27). 
O uso de cordas duplas é uma técnica que se aplica a alunos de violoncelo de nível intermediário. Nessa peça, em particular, esse uso ocorre de maneira simples, pela escolha das notas do pedal, e torna-se de fácil execução para os estudantes. Também permite que os estudantes consigam realizar o pedal visando diferentes nuances de dinâmica e intenção musical, pois as notas propostas não oferecem grandes desafios técnicos.

Em relação às texturas utilizadas por Villa-Lobos e sua aplicação com fins didáticos nas Cirandinhas, Shimabuco (2012) ressalta algumas das características abordadas pelo compositor, entre elas, "o uso de pedais e ostinatos, de dobramentos e paralelismos, de textura simples e de sobreposição de texturas com componentes complementares" (SHIMABUCO, 2012, pp. 32-50). No que diz respeito à sua aplicação na adaptação para violoncelos, esses recursos mostram-se favoráveis à pedagogia do instrumento, tendo em vista que os alunos de nível intermediário utilizam, basicamente, a extensão de três oitavas do violoncelo. Os recursos empregados possibilitam que mais de uma voz possa ser executada na mesma região melódica do instrumento, evitando notas muito agudas, que já fazem parte da técnica avançada do violoncelo.

Sobre o uso de pedais e ostinatos, Shimabuco (2012) considera "tanto as notas pedais como os ostinati como recursos de reiteração com o potencial de oferecer fundamentação horizontal a ousados procedimentos verticais" (SHIMABUCO, 2012, p. 38). Em termos didáticos, no que diz respeito à adaptação para violoncelos da Cirandinhas $\mathrm{n}^{\circ}$ 9, a alternância do pedal entre as diferentes vozes, ora executado pela voz superior, ora pela voz inferior, possibilita que os instrumentistas de ambas as vozes se alternem nos papeis de melodia e acompanhamento. Dessa forma, podem ser trabalhadas diferentes qualidades e características musicais presentes nesses papeis, proporcionando, também, maior envolvimento dos alunos com a proposta.

Outra característica do tratamento das texturas utilizada por Villa-Lobos e citada por Shimabuco (2012) diz respeito aos dobramentos e paralelismos. Segundo a autora, o intervalo mais utilizado por Villa-Lobos para executar essa ideia é o intervalo de terça, pois esse é um intervalo bastante acessível ao estudante de piano, em função da pouca abertura de mão exigida. Villa-Lobos utiliza alguns poucos dobramentos na Cirandinhas $\mathrm{n}^{\circ}$ 9, que ocorrem também em intervalos de terça. Esse intervalo é bem-vindo na execução ao violoncelo, pois proporciona facilidade para a afinação dos intervalos, também proporcionando um efeito de 
divisi entre as vozes, além de manter proximidade entre as linhas melódicas, sem necessidade da realização de mudanças de posição muito distantes, tornando a peça acessível aos estudantes de nível intermediário.

Shimabuco (2012) ressalta, ainda, a restrição de espaço textural, a sobreposição de camadas em um mesmo espaço textural e a utilização de texturas simples pelo compositor nas peças que compõem as Cirandinhas. Segundo a autora, essas texturas facilitam a execução pianística pelos estudantes, pois em tais peças "não se pode lançar mão de grandes densidades, espaços ou complexidades texturais" (SHIMABUCO, 2012, p. 46). Essa justificativa se aplica também no caso de peças direcionadas a estudantes de violoncelo, pois a densidade de texturas dificulta, entre os alunos, a compreensão da afinação dos intervalos, bem como a relativização da importância das diferentes vozes. Além disso, evita o uso de grandes saltos e extensões melódicas, o que contribui para uma abordagem com fins didáticos e possibilita, como já foi citado anteriormente, que as vozes transitem no mesmo espaço de três oitavas, que é o espaço alcançado pelos alunos de nível intermediário, que ainda não utilizam com frequência as notas pertencentes à quarta oitava do violoncelo.

As propostas de inserção e ênfase das qualidades imitativas, recurso utilizado pelo compositor em muitas peças, como por exemplo, Bachianas $\mathrm{n}^{\circ} 1$, Bachianas $\mathrm{n}^{\circ} 4$, Il bove, entre outras, foi empregado na proposta educativa também com o objetivo de evidenciar as "paisagens internas" dos alunos, (MACHADO, 2015, p. 47), paisagens essas presentes em todo o ser humano, evidenciadas nos processos criativos da criança e que, pouco a pouco, vão sendo deixadas de lado no mundo adulto. Machado (2015), ao considerar as paisagens internas, tece uma relação metafórica com uma floresta povoada por muitas árvores de diferentes formatos e configurações.

As árvores da frente são prêt-à-porter, estão sempre à disposição para ser utilizadas, de modo mecânico, com eficiência prática. Já as do fundo guardam a seiva da possibilidade de transformação humana, embora muitas vezes estejam dentro de nós emboloradas e quase secas, como jornais velhos empilhados em prateleiras no sótão, porque nem sempre sabemos o que fazer com esse tesouro dentro de nós (MACHADO, 2015, p. 47) 
Segundo a autora, a medida que a criança cresce, as árvores que não fazem "sentido para o mundo socialmente aceitável" (MACHADO, 2015, p. 48) passam a ser "obscuras". "O desconhecido não é mais uma aventura, mas passa a ser um terreno no mínimo perigoso, algo que não fala mais, não move a curiosidade e, portanto, não alimenta a possibilidade de conhecer" (MACHADO, 2015, pp. 48-49). A arte seria, então, a possibilidade de trazer para a superfície as paisagens escondidas através do "estado de encantamento", também denominado por Machado de "estado de infância"15. A autora considera que "a arte, qualquer arte, permite esse trânsito compreensível pelos significados fundamentais da vida humana" (MACHADO, 2015, p. 45). Nesse sentido, a utilização de propostas relacionadas à imitação, evidenciam, também, um processo narrativo, similar ao utilizado na narrativa oral, o que, sob minha concepção, além de tudo o que já foi dito sobre a arte, enfatiza o acesso às paisagens internas individuais e coletivas.

\section{Considerações e reflexões:}

Durante a realização do trabalho foi possível tecer algumas considerações, tanto de ordem técnica e musical, quanto em relação ao processo educativo. Foi possível realizar algumas reflexões em diálogo com as proposições de Machado (2015), levando em consideração o ensino e aprendizagem na infância e sua transposição para o mundo adulto. Também foi possível relativizar os conceitos de infância e considerar a abordagem proposta possível de ser aplicada também a outras faixas etárias, enfatizando o estado de infância para a realização e prática musical.

Os alunos envolvidos na proposta em Porto Alegre demonstraram interesse e motivação para o estudo e performance da peça, sendo destacada por eles a ideia de que a adaptação "dava a impressão de que a peça teria sido escrita originalmente para violoncelos”. Tal consideração

15 Informação fornecida por Machado durante a disciplina Arte de palavra e a aprendizagem artística, ministrada pelo Programa de Pós-graduação em Artes Visuais da Escola de Comunicações e Artes da Universidade de São Paulo, São Paulo, 2019. 
apoia a abordagem da proposta, que se mostrou, também, segundo os alunos, adequada às características idiomáticas do instrumento, além de destacar nuances específicas do "conjunto de violoncelos". Os alunos demonstraram que se sentiram valorizados ao executarem uma peça de compositor brasileiro, violoncelista, e que possui obras originais para o instrumento. Tais aspectos agregaram importância ao trabalho e também ao estudo individual de cada aluno, além de desenvolver a curiosidade em conhecer outras peças de Villa-Lobos.

Os alunos que participaram do trabalho não tinham familiaridade com a melodia Carneirinho, carneirão, utilizada por Villa-Lobos na composição da peça. Essa observação considera a possibilidade de que eles estejam afastados de parte da bagagem cultural da tradição oral do seu país, apontando para a necessidade de aproximá-los a esses conteúdos, por ser a tradição oral importante fonte de conhecimento e de desenvolvimento de possibilidades educativas. Entretanto, a performance da peça possibilitou que os alunos se apropriassem dessa melodia, incorporando-a às suas vivências, e acrescentando elementos constituintes dessa tradição.

A proposta enfatizou o potencial pedagógico da peça abordada e, talvez de outras peças de Villa-Lobos, destacando sua viabilidade em instrumentos que não os originalmente indicados pelo compositor e enfatizando a aproximação com o estado de infância, conforme proposto por Machado (2019). Quinteiro (2002), ao relatar sobre a situação das pesquisas brasileiras envolvendo o universo infantil nos anos de 2002, relata que "a contribuição não pode ficar restrita apenas ao conhecimento da situação da criança, mas, sobretudo, das culturas infantis" (QUINTEIRO, 2002, p. 30). A autora cita um texto de Bastilde (1979), o qual considera que "para estudar a criança, é preciso tornar-se criança, não basta observar a criança, de fora, como também não basta prestar-se atenção a seus brinquedos; é preciso penetrar, além do círculo mágico que dela nos separa, em suas preocupações, suas paixões, é preciso viver o brinquedo" (BASTILDE, 1979, p. 154 apud QUINTEIRO, 2002, p. 30). Nesse sentido, acredito que a proposta do trabalho realizado dialoga com essa ideia, ao sugerir que os alunos e professores envolvidos possam adentrar nesse universo e acessar seus processos imaginativos e seu estado de infância.

As considerações de Quinteiro (2002) refletem, ainda, muito da situação atual da infância da criança brasileira e nos fazem questionar nosso próprio fazer como professores de música. A autora sinaliza que "gerações inteiras foram e continuam sendo comprometidas pela 
supressão de sua infância" (QUINTEIRO, 2002, p. 31), em alusão ao proposto por Martins (1993), que ressalta que as crianças brasileiras são "os filhos da dívida externa, os filhos do estado oligárquico-desenvolvimentista, os filhos da ditadura" (MARTINS, 1993, pp. 9-13 apud QUINTEIRO, 2002, p. 31) e tantos outros adjetivos que poderíamos acrescentar a esses. Porém, Machado considera que, "as crianças sabem muito mais do que supomos. O que ocorre é que as escolas, em geral, desviam e amarram a atenção das crianças no cabresto do binômio certo/errado" (MACHADO, 2015, p. 18)

Sob essa concepção e com inspiração nas reflexões dos autores citados, considero que a abordagem proposta soma-se a outras iniciativas que buscam contextualizar a criança e a aprendizagem dentro de uma proposta de valorização do seu universo, aproximando a atividade do fazer musical com propostas lúdicas, próprias do estado de infância. Villa-Lobos, tradicionalmente, vem sendo visto como um compositor que se dedicou à valorização do universo do cancioneiro musical do Brasil, na tentativa de recolocar esse universo no centro do repertório de concerto da música brasileira. Considero importante, também, de nossa parte como professores de música, valorizarmos as propostas de Villa-Lobos e nos somarmos a elas, principalmente no que diz respeito à investigação do universo infantil e ao desvelamento da infância. Ressalto que acredito existir um longo caminho a ser trilhado, diferentes músicas ainda a serem "descobertas", principalmente as que dizem respeito ao universo de infâncias ainda desconhecidas, situadas nos recantos mais profundos do Brasil. Proponho, assim, que o trabalho desenvolvido com a Cirandinhas $\mathrm{n}^{\circ} 9$ e relatado parcialmente neste texto, possa vir a integrar esse esforço na valorização do universo infantil da criança brasileira. 


\section{Referências}

BASTILDE, Roger. Prefácio. In: FERNANDES, Florestan. Folclore e mudança social na cidade de São Paulo. Petrópolis, Vozes, 1979, p. 153-155.

BRIETZKE, Marta; VILLENA, Marcelo. Integração de conbecimentos de professor de violoncelo e compositor para a elaboração de repertórios didáticos. In: IV Mostra de Violoncelos de Natal, Natal, Anais..., 2014.

CARRASQUEIRA, Toninho. Divertimentos-Descobertas: estudos criativos para o desenvolvimento musical - sopros e cordas friccionadas. São Paulo: EDUSP, 2017

CARVALHO, Maria Salete de. Iniciação ao violoncelo: Análise de três métodos e proposta de sua suplementação com repertório do folclore brasileiro. 2010. 131 f. Dissertação (Mestrado em Música) - Centro de Letras e Artes- Universidade Federal do estado do Rio de Janeiro, Rio de Janeiro, 2010.

EMMERSON, Simon. The language of eletrocaustic music. London: The Macmillan Press, 1986.

FRAGA, Eduardo Fraga. O idiomatismo nas composições para percussão de Luiz D'Anunciação, Ney Rosauro e Fernando Iazzetta: análise, edição e performance de obras selecionadas. In: XV Congresso da ANPPOM, Rio de Janeiro. Anais...2005.

FONTERRADA, Marisa Trench de Oliveira. De tramas e fios: um ensaio sobre música e educação. São Paulo: UNESP; Rio de Janeiro: Funarte, 2008.

HYER, Brian. Tonality. In: GROVE Music Online. Oxford: Oxford University Press, 2019. Disponível em: https://doi.org/10.1093/gmo/9781561592630.article.28102. Acesso em: 18 de julho de 2019. 
LAGO, Manoel Corrêa; BARBOZA, Sérgio; BARBOSA, Maria Clara. Heitor Villa-Lobos: Guia Prático para a educação artística e musical. Rio de Janeiro: ABM: Funarte, 2009.

MACHADO, Regina. A arte de palavra e da escuta. São Paulo: Editora Reviravolta, 2015.

MARTINS, José de Souza. O massacre dos inocentes: a criança sem infância no Brasil, 2 ed. São Paulo, Hucitec, 1993.

OSTINATO. In: GROVE Music Online. Oxford: Oxford University Press, 2019. Disponível em: https://doi.org/10.1093/gmo/9781561592630.article.20547. Acesso em: 18 de julho de 2019. PADOVANI, José; FERRAZ, Silvio. Proto-história, evolução e situação atual das técnicas estendidas na criação musical e na performance. Música Hodie, Belo Horizonte, v. 11, n. 2, p. 11-35, 2011. PEREIRA, F. V. As práticas de reelaboração musical. Tese de Doutorado, Universidade de São Paulo, São Paulo, Brasil. 2011.

PILGER, Hugo. Heitor Villa-Lobos: o violoncelo e seu idiomatismo. Curitiba: CRV, 2013

QUINTEIRO, Jucirema. Infância e educação no Brasil: um campo de estudos em construção. In: FARIA, Ana Lúcia; DEMARTINI; Zeila, PRADO, Patrícia (orgs). Por uma cultura da infância: metodologias de pesquisa com crianças. Campinas: Autores Associados, 2002.

REGO, Eusiel; GLOEDEN, Edelton. Os movimentos sucessivos em oitavas em Haydn e Mozart. In: DAPesquisa. V. 5, n. 7, 2010, pp. 259-280)

SALLES, Paulo de Tarso. Villa-Lobos: processos composicionais. Campinas: Editora da Unicamp, 2009.

SHIMABUCO, Luciane. Cirandinhas de Heitor Villa-Lobos: inventividade textural em restrições impostas por propósitos didáticos. In: II Simpósio Villa-Lobos Anais..., São Paulo, SP, Brasil.2012. 
SILVA, Teresa Cristina Rodrigues; AQUINO, Felipe Avellar de; PRESGRAVE, Fabio Soren. Violoncelo XXI: estudos para aprender a tocar e apreciar a linguagem da música contemporânea. São Paulo: Editora urbana, 2012.

SOUZA, Sanny. A educação musical através do violoncelo. 1998. 37 f. Monografia (Licenciatura em Música) - Centro de Letras e Artes, Universidade do Rio de Janeiro, Rio de Janeiro, 1998.

SUETHOLZ, Robert John. A pedagogia do violoncelo e aspectos de técnicas de reeducação corporal. 2011.141f. Tese (Doutorado). Escola de Comunicações e Artes, Universidade de São Paulo, São Paulo, 2011.

TEXTURA. In: GROVE Music Online. Oxford: Oxford University Press, 2019 disponível em: https://doi.org/10.1093/gmo/9781561592630.article.2775. Acesso em: 18 de julho de 2019.

VILLA-LOBOS, H. Cirandinhas: coleção de I 2 peças fáceis sobre temas de rodas infantis para piano. Rio de Janeiro: Arthur Napoleão. (s.d.).

VILLA-LOBOS, H. Cirandinha $n^{\circ}$ 9: Carneirinho, Carneirão. [S. 1.: s. n.], 2016. 1 vídeo (3:21 min). Disponível em: https://youtu.be/oYhmDvMyvJU. Acesso em: 18 de julho de 2019. 